\title{
Childhood Sexual Abuse, Other Childhood Factors, and Pathways to Survivors' Adult Relationship Quality
}

\author{
Eric C. Walker \\ Brigham Young University - Provo \\ Thomas B. Holman \\ Brigham Young University - Provo \\ Dean M. Busby \\ Brigham Young University - Provo, dean_busby@byu.edu
}

Follow this and additional works at: https://scholarsarchive.byu.edu/facpub

Part of the Other Social and Behavioral Sciences Commons

\section{Original Publication Citation}

Walker, E. C., Holman, T. B., \& Busby, D. M. (2009). Childhood sexual abuse, other childhood factors, and pathways to survivors' adult relationship quality. Journal of Family Violence, 24, 6, 397-407.

\section{BYU ScholarsArchive Citation}

Walker, Eric C.; Holman, Thomas B.; and Busby, Dean M., "Childhood Sexual Abuse, Other Childhood Factors, and Pathways to Survivors' Adult Relationship Quality" (2009). Faculty Publications. 4608. https://scholarsarchive.byu.edu/facpub/4608 accepted for inclusion in Faculty Publications by an authorized administrator of BYU ScholarsArchive. For more information, please contact ellen_amatangelo@byu.edu. 


\title{
Childhood Sexual Abuse, Other Childhood Factors, and Pathways to Survivors' Adult Relationship Quality
}

\author{
Eric C. Walker • Thomas B. Holman • Dean M. Busby
}

Published online: 12 May 2009

(C) Springer Science + Business Media, LLC 2009

\begin{abstract}
We were interested in understanding how the effects of childhood sexual abuse, in concert with other negative childhood experiences, were carried forward into adult romantic relationships. Data from 15,831 married or cohabitating individuals were gathered via the RELATE Questionnaire. Empirical research, attachment theory, and a general model of adult relationship quality suggested that the path from negative childhood events to adult relationship quality was mediated by a number of individual and relational affect-laden variables. Results showed that childhood abuse and other family-of-origin variables work primarily through the adult survivor's perceptions of the events of his or her childhood. This "current impact" variable, along with the current level of depression, work through an emotion-laden relationship variable-level of emotional flooding during couple conflict - to influence the relationship quality outcome variable. Treatment implications are discussed.
\end{abstract}

Keywords Child sexual abuse · Relationship quality · Emotional health $\cdot$ Path model

Few problems receive more attention in the media and in legislative initiatives than childhood sexual abuse. This attention reflects a societal view that childhood sexual abuse is not only a heinous crime, but that it can have long-

E. C. Walker $(\bowtie) \cdot$ T. B. Holman · D. M. Busby

School of Family Life, Brigham Young University,

1316 North 300 West,

Provo, UT 84604, USA

e-mail: ekwalk@msn.com

T. B. Holman

e-mail: thomas_holman@byu.edu

D. M. Busby

e-mail: dean_busby@byu.edu term negative influences on the victims. Indeed, prior research on childhood sexual abuse survivors suggests increased negative life conditions and circumstances, such as increased depressed moods, lower self-esteem, poorer affect regulation, poorer communication and conflict management skills, and lower relational quality (Bacon and Lein 1996; Cherlin et al. 2004; Edwards and Alexander 1992). Yet, there may not be an isolated or straightforward relationship between the sexual abuse of children and adult variables such as relational quality. Researchers suggest that childhood sexual abuse is only one of a number of childhood stressors that impact adult relationship or marital outcomes (Edwards and Alexander 1992). Furthermore, there is some indication that part of childhood sexual abuse's influence may be indirect via mediating factors (Busby et al. 2005).

As yet, there has not been a comprehensive study to explore multiple negative childhood experiences, including childhood sexual abuse, and mediators related to adult romantic relationship outcomes. The purpose of this investigation was to understand the role of childhood sexual abuse in adult relationship quality outcomes via other adult mediating variables, while controlling for family of origin stressors. Said another way, we are interested in finding out how childhood sexual abuse and other negative childhood experiences are carried forward into adult romantic relationships.

\section{Literature Review}

Childhood sexual abuse has been the subject of a vast body of research (Kendall-Tackett et al. 1993). Understanding the adult effects of childhood sexual abuse is complicated because the list of associated conditions, such as depressed 
moods, overwhelming emotions, and lower relational quality (Bacon and Lein 1996; Cherlin et al. 2004; Edwards and Alexander 1992), is so large that " $[t]$ here is virtually no general domain of symptomatology that has not been associated with a history of sexual abuse" (Kendall-Tackett et al. 1993, p.173). Researching the adult effects of childhood sexual abuse is even more complex because the effects of childhood sexual abuse vary greatly among adult survivors (Berliner and Elliott 2002).

Research findings become even more convoluted because a history of sexual abuse is frequently not the only negative influence in a survivor's childhood experience. Other adverse childhood experiences have been shown to occur more frequently among those reporting a history of childhood sexual abuse, such as other forms of abuse or neglect (Dong et al. 2004), dysfunctional or unhealthy family-of-origin patterns such as witnessing domestic violence and parental marital discord (Swanston et al. 2003), and stressful family-of-origin circumstances including living with household members who are substance abusers, mentally ill, or involved in criminal activities (Dong et al. 2004).

With the broad array of correlations between childhood sexual abuse, other family-of-origin experiences, and adult living, we turn to theory and research to clarify the interactions of multiple childhood and adult variables as well as to identify mediators for carrying the effects from a history of childhood sexual abuse to adult romantic relationship quality.

What is the Path from Childhood Sexual Abuse to Adult Relationships?

Attachment theory (Bowlby 1973; Johnson 2004), with a focus on the emotional and transactional processes of individuals in relationships from childhood to adulthood, provides an insightful perspective. The theory suggests that humans have an innate need to form close bonds with other human beings. The more an individual's attachment needs are met, the more emotionally healthy the person will be. Positive attachment in childhood creates a safe haven in times of stress and anxiety. On the other hand, family-oforigin circumstances such as caregivers who are inaccessible, who are unresponsive to the child's attachment-seeking behaviors, or who respond with abuse or neglect create insecurity in children. Children's beliefs and expectations about self, others, and relationships can carry forward through childhood and adolescence to influence their experiences in adult romantic relationships (Sroufe et al. 2005).

The two most important attachment relationships are between parent/caregiver and child, and between adult romantic partners. In these attachment relationships, the strongest emotions arise and have the most influence. The working models and behavioral systems that an individual constructs determine both the interpretation of other actions as well as coping strategies used in relationships (Simpson et al. 2007). Attachment theory therefore "addresses how relationship partners deal with their emotions, process and organize information about self and other, and communicate with loved ones" (Johnson 2004, p.36). Based on attachment theory, we can assume that a history of negative experiences, such as sexual abuse, will be related to more negative perceptions of intimate relationships, self, and more negative emotional experiences in relationships. This also suggests that mediating variables between childhood sexual abuse and adult relational quality may be found in a sexual abuse survivor's perceptions of self and relationships, and in couples' emotional responses to relational interactions.

This assumption of mediating factors between childhood and adult relational quality has been tested and supported in previous research. Holman (2001) reviewed more than 60 years of theory and research on premarital predictors of later marital quality or breakup. A model of marital quality was proposed based on this research and theories, including attachment, developmental, and ecological theories. In this model, marital quality was predicted by four factors: (1) childhood and family-of-origin factors, such as parent-child relationship and parents' marital quality, (2) adult individual characteristics, attitudes, and personality, such as emotional health, (3) social contexts, such as social network connections, and (4) couple interactional processes, such as positive communication. Results of the subsequent longitudinal study of 376 couples suggested that couple interactional processes are the strongest direct predictor of marital quality. Childhood and family-of-origin factors had small, but significant direct effects. However, individual characteristics, social context, and couple interaction processes acted as full or partial mediators between family-of-origin factors and adult marital quality.

This suggests that childhood factors can have a direct influence on adult relational quality; however when other adult variables are included, specifically individual characteristics, social context, and couple interaction factors, the effects between childhood measures and adult relational quality will be fully or partially mediated. These findings begin to suggest paths of influence from childhood experiences to adult relationships.

Is Childhood Sexual Abuse Related to Adult Relationship Quality?

Consistent with the Holman (2001) model, researchers have repeatedly reported direct relationships between childhood sexual abuse and lower relational quality in adulthood. Compared to individuals reporting no history of childhood 
sexual abuse, abuse survivors are less likely to report highest levels of overall relationship satisfaction (DiLillo and Long 1999; Mullen et al. 1994). Lower relationship stability, in the form of separation or divorce, has also been repeatedly associated with histories of childhood sexual abuse (Cherlin et al. 2004; Colman and Widom 2004; Mullen et al. 1994). Cherlin et al. (2004) found that women with no abuse history were more likely to be currently married than cohabiting or single. Women with a history of abuse, particularly sexual abuse, were also more frequently found in "transitory unions." These unions were typically shorter cohabiting unions with briefer time periods between the ending of one and the beginning of the next relationship.

What Specific Factors Mediate The Impact of Childhood Sexual Abuse?

Very little research has identified mediating factors between childhood sexual abuse and adult relational quality. For this reason, an important research endeavor is to identify potential mediators. One of the mediators specifically related to childhood sexual abuse is the adult survivor's perception that his or her childhood and family-of-origin experiences currently impact adult relations (Martinson 2005). For example, the association between family-oforigin and adult self-esteem acts through a perception that childhood and family-of-origin issues are currently having a negative impact on adult functioning (Busby et al. 2005).

Other potential mediators have not been tested, but can be inferred. There is a relationship between childhood sexual abuse and adult mood disorders, especially depression (Swanston et al. 2003). Evidence also suggests a relationship between childhood sexual abuse and affect regulation. Survivors may experience heightened stress in anticipation of, or more sensitivity to, interpersonal conflict (Jack et al. 1995). Survivors of childhood sexual abuse might be sensitized to relatively minor stresses, such as an argument with a husband over trivial issues, or hearing that a brother made a snide remark. This could result in Acute Stress Disorder symptoms or higher stress reactions by abuse survivors to lower stress incidents (Koopman et al. 2001). A potential mediating influence is suggested when we consider the negative associations that exist between adult depression, emotional flooding during conflict, and relational quality (Davila et al. 2003; Whisman et al. 2004). In other words, childhood sexual abuse is related to increased adult depression and decreased emotional regulation or emotional flooding. Increased adult depression and emotional flooding are related to decreased adult relational quality. Whether or not an actual mediating relationship exists still needs to be tested.

\section{Path Model}

Based on theoretical foundations and empirical research, we created a model to test the relationship between childhood sexual abuse and adult relational quality. This model contained negative family-of-origin events and processes such as childhood sexual abuse, family-of-origin violence, and multiple childhood stressors. Mediating factors, such as perception of current impact of negative family-of-origin experiences, adult depression, and emotional flooding during conflict, were selected to address the potential mediating effects of individual characteristics and couple interactional processes described in the Holman (2001) model.

Negative childhood events, including sexual abuse, were likely related to adult relationship quality, but the direct effects of these events and processes were anticipated to be small. These negative childhood events, given their emotional content, were likely related to the adult relationship outcomes via intervening personal and relational factors. The attachment perspective we articulated suggests that a primary "carrier" of the emotions of the negative childhood events and processes would be the adults' continued negative processing about these past family experiences. We hypothesized two such carrier variablescurrent impact of family-of-origin events and process, and depression. We also anticipated that these two factors would be related to emotion-laden couple interactions of the adult intimate relationship, and chose a variable called emotional flooding during couple conflict as an indicator of that concept. Furthermore, we conjectured that this variable would be a mechanism for bringing forward into the current relationship the affect/emotion of childhood happenings and current impact of those happenings. The model we test in this study is illustrated in Fig. 1.

\section{Method}

Participants and Procedures

The cross-sectional data came from the RELATionship Evaluation (RELATE), and included responses from 15,831 individuals in marital or cohabiting relationships collected from 1999 to 2007 via the Internet as part of college family studies or sociology classes, as part of workshops for premarital couples, at the request of professional therapists or clergy, or via search engines online. The RELATE is a 274-item questionnaire designed to assess four major predictors of premarital and marital relationship quality and stability. RELATE in its current form has been in use since 1997 and is the result of an extensive process of multiple pilot studies, preliminary factor analysis, test-retest 
Fig. 1 Path model of relationships between childhood measures and relationship quality

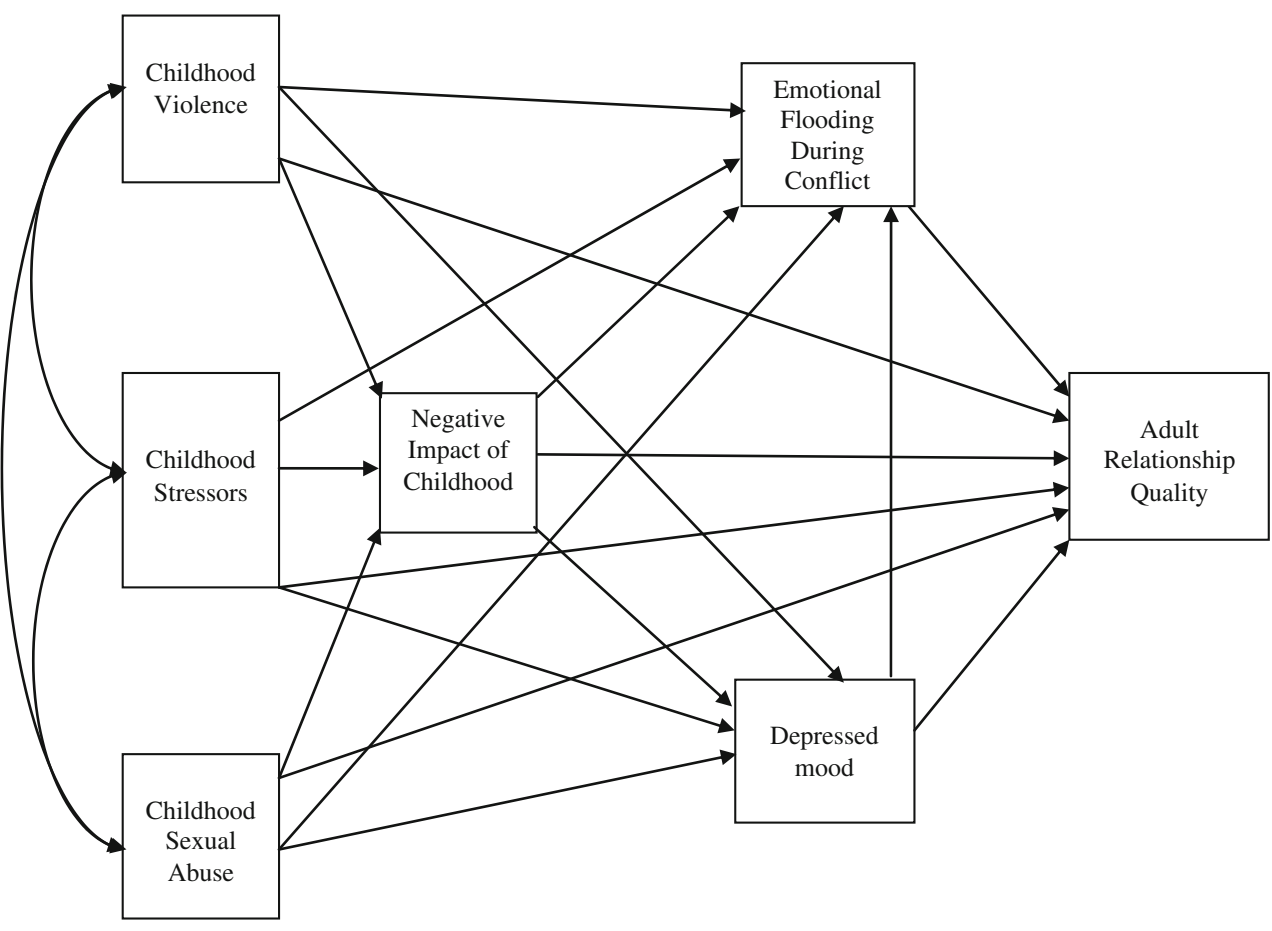

analysis, and internal consistency analysis. For details on reliability and validity analyses as well as the conceptual model behind the survey see Busby et al. (2001).

Fifty-seven percent of the couples in our study were married at the time of the assessments (47\% first marriage and $10 \%$ remarried). Thirty-six percent of the couples were living with a partner in an intimate, unmarried relationship. A history of divorce is reported by $7 \%$ of the respondents. Thirty-nine percent of the participants were male and $56 \%$ of the participants were female; $5 \%$ did not report gender. The mean age of participants was 35 years of age. The most frequent racial and ethnic profile was $86 \%$ Caucasian, followed by 3\% African American, 3\% Asian, 3\% Latino, $2 \%$ mixed/biracial, $2 \%$ Other, and 1\% Native American.

\section{Measurements}

"Childhood sexual abuse" included physical contact, i.e. fondling, penetration, etc. (DiLillo and Long 1999; Larson and Lamont 2005). The self-reported childhood sexual abuse item must have occurred to the respondent before age 18 (Cherlin et al. 2004; Finkelhor et al. 1990; Larson and Lamont 2005). History of abuse included intra- and/or extra-familial abuse. Response options were treated as a frequency variable including never, rarely, sometimes, and often. Higher numbers reflected more frequent sexual abuse victimization.

"Childhood violence" was a scale comprising four questions, three of which asked "How often was your father violent towards your mother?" "How often was your mother violent towards your father?" and "How often were you violent in your family?" The fourth question addressed the general frequency of violence, "Considering all of your experiences while growing up in your family, how would you rate the general level of violence in your home?" Responses included five options ranging from "There was never violence in the home" to "There was very often violence in the home." Violence may have taken the forms of "slapping, pushing, kicking, hitting hard with a fist, hitting with objects or other types of violence." A higher scale score indicated greater frequency of violence in the home with a standardized Cronbach's alpha of .76.

The "childhood stressors" scale was measured by four different types of stressors: "In my immediate family while I grew up" (1) "there were family members who experienced emotional problems such as severe depression, anxiety attacks, eating disorders, or other mental/emotional problems," (2) "there were one or more family members who struggled with addictions to alcohol or other drugs," (3) "there were physical strains such as a member(s) being physically handicapped, hospitalized for a serious physical illness or injury, or becoming premaritally pregnant," and (4) "there were financial strains such as loss of jobs, bankruptcy, large debts, or going on welfare." Five possible responses for each type of stressor ranged from never to very often. A higher scale score suggested more frequent occurrence of negative childhood stressors with a standardized Cronbach's alpha of .63.

A "current impact of childhood events and processes" scale was created with four choices: "From what I experienced in my family, I think family relationships are confusing, unfair, anxiety-provoking, inconsistent, and 
unpredictable," "There are matters from my family experience that I'm still having trouble dealing with or coming to terms with," "There are matters from my family experience that negatively affect my ability to form close relationships" and a reverse-coded "From what I experienced in my family, I think family relationships are safe, secure, rewarding, worth being in, and a source of comfort." Five response options were available ranging from strongly disagree to strongly agree. Higher scores represented a report of higher perception of current negative impact regarding the family of origin with a standardized Cronbach's alpha of 83 .

Similarly, the adult scale of "depressed mood" was measured by asking "How much do these words or phrases describe you?" Response options ranged from never to very often. The scale comprised five variables, describing self as "sad and blue," "feel hopeless," "depressed," and two reverse-coded items: "I take a positive attitude toward myself" and "I feel I am a person of worth." Higher scores show elevated reports of depressed moods with a standardized Cronbach's alpha of .84 .

"Emotional flooding during conflict" scale was created by taking the mean of three questions addressing the frequency of "whenever I have a conflict with my partner, I feel physically tense and anxious, and I don't think clearly," "I feel physically tired or drained after an argument with my partner," and "Whenever we have a conflict, the feelings I have are overwhelming." The five response options range from never to very often. Higher scores reflected higher emotional flooding. Standardized Cronbach's alpha was .80 .

The "adult relationship quality" scale was composed of nine variables. Participants were asked "How often have you thought your relationship was in trouble?" "How often have you and your partner discussed ending your relationship?" and "How often have you broken up or separated and then gotten back together?" and how satisfied they were with the following: "the physical intimacy you experience," "the love you experience," "your overall relationship satisfaction," "how conflicts are resolved," "the amount of relationship equality you experience," and "the quality of your communication." Five response options ranged from never to very often or very dissatisfied to very satisfied, depending on the question. Higher scores represented higher quality. Standardized Cronbach's alpha was .90.

\section{Analysis}

Following Holman's (2001) theoretical model of marital quality, and in accordance with prior literature, we tested a path model using AMOS 7.0 in which all negative childhood experiences were directly related to all adult measures of current impact of childhood events and processes, adult depressed mood, emotional flooding during conflict, and adult relationship quality (see Fig. 1). The three childhood vulnerabilities, including childhood sexual abuse, were correlated with each other to control for the effect of correlation described in prior literature. Also tested were the direct relationship between current impact of childhood events and processes, depressed mood, and emotional flooding during conflict.

The initial model was subsequently simplified or "trimmed" on the basis of the statistical significance and effect size of the model parameters. The objective of model trimming was a combination of finding an adequate model fit, and maintaining a balance between parsimony through eliminating insignificant and low explanatory relationships and keeping the relationships that were necessary to test the hypothesis and tell the story of the correlation between childhood sexual abuse and adult relational satisfaction and stability.

Due to the large sample size, we anticipated that even very small and relatively unimportant paths would be significant; therefore we selected severe criteria for inclusion in the final model. A significance level below .001 was selected as the criterion for significance. Further, we eliminated all paths below .05 standardized regression weights (Busby et al. 2008). Large sample size and model trimming affect some model fit statistics, such as elevating the chi-square. Taken alone this statistic may not accurately represent model fit. Therefore, four fit statistics chi square, Comparative Fit Index (CFI), Tucker-Lewis Index (TLI), and Root Mean Square Error of Approximation (RMSEA) were chosen to provide a more nuanced indication of how well the model fit the data. CFI, TLI, and RMSEA are not as affected by sample size as chi square and therefore provided a balanced indication of model fit.

Missing data were a minimal problem with all mean variables reporting $2.4 \%$ or less missing data. As part of the statistical program of AMOS, missing data were handled through "a direct approach based on maximum likelihood (ML) estimation" (Byrne 2001, p.292).

\section{Results}

Twenty-two percent of this combined male and female sample self-reported a history of childhood sexual abuse. This frequency is consistent with prior research, which has reported childhood sexual abuse frequency for females ranging from at least $20 \%$ (Dong et al. 2004) up to $27 \%$ in a national survey (Finkelhor et al. 1990), and for males ranging from at least $7.8 \%$ (Lawson et al. 1998) up to $16.5 \%$ (Twaite and Rodriguez-Srednicki 2004). An examination of the individual variables indicated that skewness and kurtosis were within appropriate ranges (see Table 1). 
The first analysis we performed was the bivariate correlation between child sexual abuse and relationship quality. As noted in Table 1, the correlations ranged from -.11 (childhood sexual abuse and adult relationship quality) to -.50 (emotional flooding and adult relationship quality). Thus, our initial finding was consistent with some previous literature suggesting the possibility of a direct relationship between childhood sexual abuse and adult relationship quality. Consistent with theory and previous research, the relationship between childhood experiences, such as sexual abuse, and adult relationship quality was small.

The second question was whether childhood sexual abuse, in concert with other measures of childhood experiences, and working through theoretically reasonable mediating adult variables, was related directly to adult relationship outcomes. We answered this question by testing the model in Fig. 1 using structural equation modeling techniques.

The final model is shown in Fig. 2. Model fit statistics suggested good fit with the data as three out of the four statistics were well within range $\left(\chi^{2}=64, d f=8, p=<.001\right.$, $\mathrm{CFI}=.998$, TLI $=.997$, and $\mathrm{RMSEA}=.021$, with a $90 \%$ confidence level of .016 to .026). As suggested in prior literature, all three childhood measures were moderately correlated with one another. Thus, the more physical violence in the family of origin, the more stress regarding such things as alcohol and drug use or mental illness, and the greater the incident of childhood sexual abuse. We note that childhood sexual abuse had the weakest relationship of the three family-of-origin factors with the current negative impact variable, but it was the only one of the three with a significant direct relationship to depression.

The primary intervening factors carrying forward the effects of negative childhood experiences were (1) current negative impact regarding these experiences and (2) the level of depression. Furthermore, we note the significant relationship between current negative impact and depression and both of these individual variables are related to emotional flooding during couple conflict as hypothesized. All three adult variables were significantly and negatively correlated to adult relationship quality. A decomposition of direct and indirect effects is presented in Table 2.

Our analysis suggested that emotional flooding was related to relationship quality $(\beta=-.39)$ such that the higher the emotional flooding, the lower the relationship quality. Depression was less strongly related to relationship quality ( $\beta=-.19)$ than it had been at the bivariate level, suggesting that some of its impact is subsumed by the emotional flooding factor. The current negative impact variable also demonstrated a small but statistically significant association with relationship quality $(\beta=-.08)$. Overall the model accounted for $30 \%$ of the variance in "adult relationship satisfaction" (see Table 3 for all $R^{2}$ values).

\section{Discussion}

Our primary interest in this research was to understand the pathway by which childhood sexual abuse affects later adult relationship quality while controlling for other negative childhood experiences. A review of research and theory suggested two things. First, childhood sexual abuse was but one of several interrelated family and childhood factors that could "carry forward" into adult romantic relationships. Second, there are a number of affect-laden intrapersonal and interpersonal factors that could mediate the relationship between childhood sexual abuse and adult romantic relationship quality. Based on the previous

Table 1 Means, standard deviations, and scale pearson correlations

\begin{tabular}{|c|c|c|c|c|c|c|c|}
\hline & $\begin{array}{l}\text { Childhood } \\
\text { Sex Abuse }\end{array}$ & $\begin{array}{l}\text { Childhood } \\
\text { Violence }\end{array}$ & $\begin{array}{l}\text { Childhood } \\
\text { Stressors }\end{array}$ & $\begin{array}{l}\text { Current } \\
\text { Impact }\end{array}$ & $\begin{array}{l}\text { Depressed } \\
\text { Mood }\end{array}$ & $\begin{array}{l}\text { Emotional } \\
\text { Flooding }\end{array}$ & $\begin{array}{l}\text { Relationship } \\
\text { Quality }\end{array}$ \\
\hline$M$ & 1.21 & 1.57 & 1.98 & 2.26 & 2.22 & 2.83 & 3.82 \\
\hline$S D$ & 0.50 & 0.65 & 0.85 & 0.99 & 0.64 & 0.93 & 0.84 \\
\hline Skewness & 3.58 & 1.40 & 1.08 & 0.79 & 0.96 & 0.22 & -1.04 \\
\hline Kurtosis & 16.83 & 1.99 & 0.93 & -0.17 & 1.24 & -0.42 & 1.03 \\
\hline CSA & - & 0.26 & 0.29 & 0.30 & 0.18 & 0.12 & -0.11 \\
\hline Child Viol & & - & 0.46 & 0.47 & 0.20 & 0.15 & -0.16 \\
\hline Child Stress & & & - & 0.50 & 0.23 & 0.17 & -0.12 \\
\hline Cur Impact & & & & - & 0.38 & 0.30 & -0.27 \\
\hline Dep Mood & & & & & - & 0.43 & -.39 \\
\hline Emot Flood & & & & & & - & -.50 \\
\hline
\end{tabular}

Note. All bivariate correlations are significant at the 0.01 level (2-tailed); $M=$ variable means; $S D=$ variable standard deviations; CSA = Childhood Sexual Abuse; Child Viol = Childhood Violence; Child Stress = Childhood Stressors; Cur Impact = Current Impact; Dep Mood = Depressed Mood; Emot Flood = Emotional Flooding 
Fig. 2 Path model of relationships between childhood measures and relationship quality with standardized coefficients

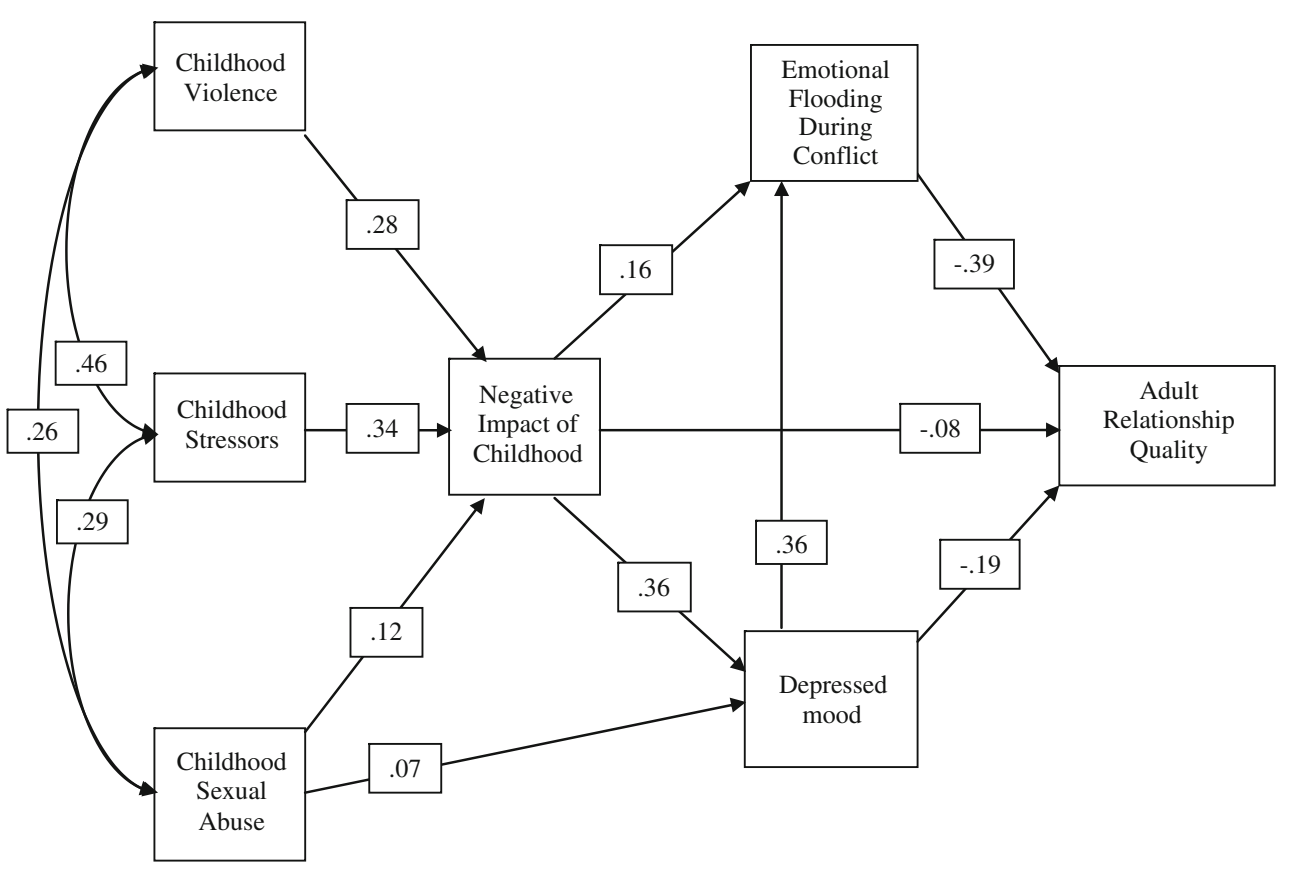

research and theoretical considerations, we tested the model shown in Fig. 1, and this resulted in the path model shown in Fig. 2.

Results of this multivariate test make three important contributions to the understanding and treatment of childhood trauma. The first important contribution is that all three childhood variables act similarly within the model and share similar paths of influence into adulthood. None of the childhood abuse or stress factors individually has a strong relationship with adult variables at a bivariate level. Together, however, the three childhood variables were able to account for a moderate influence on the perception of being negatively impacted by childhood. In other words, more types of negative childhood experiences lead to a greater perception that childhood events were influencing adult experiences (Dennerstein et al. 2004; Dube et al. 2001). Therefore, we have added to the knowledge of other negative childhood experiences, such as violence in the home and childhood stressors. In particular, all three predominantly rely on a perception that adulthood is currently and negatively impacted by childhood events. There is interplay of previous history and ongoing circumstances in which the influence of the past can be magnified or diminished depending on present factors, including an

Table 2 Standardized direct, indirect, and total effects (Independent Variables are represented horizontally on top of table and Dependent Variables are represented vertically on left of table)

\begin{tabular}{|c|c|c|c|c|c|c|c|}
\hline & & $\begin{array}{l}\text { Childhood } \\
\text { Sex Abuse }\end{array}$ & $\begin{array}{l}\text { Childhood } \\
\text { Violence }\end{array}$ & $\begin{array}{l}\text { Childhood } \\
\text { Stressors }\end{array}$ & $\begin{array}{l}\text { Current } \\
\text { Impact }\end{array}$ & $\begin{array}{l}\text { Depressed } \\
\text { Mood }\end{array}$ & $\begin{array}{l}\text { Emotional } \\
\text { Flooding }\end{array}$ \\
\hline \multirow[t]{3}{*}{ Current Impact } & Direct & .13 & .28 & .34 & - & - & - \\
\hline & Indirect & .00 & .00 & .00 & - & - & - \\
\hline & Total & .13 & .28 & .34 & - & - & - \\
\hline \multirow[t]{3}{*}{ Depressed Mood } & Direct & .07 & .00 & .00 & .36 & - & - \\
\hline & Indirect & .05 & .10 & .12 & .00 & - & - \\
\hline & Total & .11 & .10 & .12 & .36 & - & - \\
\hline \multirow[t]{3}{*}{ Emotion Flood } & Direct & .00 & .00 & .00 & .16 & .36 & - \\
\hline & Indirect & .06 & .08 & .10 & .13 & .00 & - \\
\hline & Total & .06 & .08 & .10 & .29 & .36 & - \\
\hline \multirow[t]{3}{*}{ Relation Quality } & Direct & .00 & .00 & .00 & -.08 & -.19 & -.40 \\
\hline & Indirect & -.06 & -.07 & -.09 & -.19 & -.14 & .00 \\
\hline & Total & -.06 & -.07 & -.09 & -.27 & -.34 & -.40 \\
\hline
\end{tabular}

Note. All correlations are significant at $p=.001$ level; Emotion Flood = Emotional Flooding; Relation Quality = Relationship Quality 
Table $3 R^{2}$ values

\begin{tabular}{lc}
\hline Variables & $R^{2}$ \\
\hline Current Impact & .33 \\
Emotional Flooding & .20 \\
Depressed Mood & .15 \\
Relationship Quality & .30 \\
\hline
\end{tabular}

individual's attitudes (Sroufe et al. 2005). Our results also reveal that an individual's perception of history, particularly the perception that history negatively impacts the present, is a key mediator between negative childhood experiences and adult relationship quality.

This supports the findings of Feinauer et al. (2003) in their research of childhood sexual abuse and the importance of "hardiness" for positive adult functioning. The adult attitude of hardiness is a sense that an individual influences and acts on their environment and stressors in constructive manners as opposed to the perception presented in the "current impact of childhood events and processes" that the environment, even in the past, is the principle influence on the individual.

A second important contribution is that childhood sexual abuse and other negative family events and processes are not strongly related to the adult relationship satisfaction at the bivariate level, and as the theory suggests, not directly related to relationship outcomes in the multivariate model. Rather, childhood events and processes work through adult affect-laden perceptions, feelings, and behaviors. As shown in Table 2, indirect effects play a frequent role for three out of the four adult variables. Childhood events and processes play out via individual characteristics (such as current impact and depression) and couple process variables (such as emotional flooding). As the Holman (2001) model predicts, family background variables do not necessarily account for large amounts of the variance in adult relationship outcomes. Thus, the path coefficients and effects in our findings are generally modest in size. However, again, as theory suggests, an accumulation of multiple indirect effects of these background factors may be substantial (Holman 2001).

Adult depressed mood is directly influenced by two variables (childhood sexual abuse and current impact of childhood), and indirectly influenced by three variables (childhood sexual abuse, childhood violence, and childhood stressors). Similarly, emotional flooding during conflict is directly influenced by two variables (current impact of childhood and depressed mood), and indirectly influenced by four variables (childhood sexual abuse, childhood violence, childhood stressors, and current impact of childhood). Even more striking, adult relationship quality is directly influenced by three variables (current impact of childhood, depressed mood, and emotional flooding during conflict) and indirectly influenced by five variables (childhood sexual abuse, childhood violence, childhood stressors, current impact of childhood, and depressed mood). Interestingly, the two variables that have the most direct and indirect effects on other variables are childhood sexual abuse and current impact of childhood.

Considering the importance of mediating variables in this model, we provide an important perspective to consider when evaluating the variety and sometimes inconsistent results of prior research. The role of mediators has largely been ignored in the study of childhood sexual abuse and adult relationship outcomes. If mediating factors play such an important role, it is not surprising that excluding this aspect of research could lead to varying and occasionally conflicting results in studies of adult relationships (Mullen et al. 1994).

The small relationship between childhood sexual abuse and adult measures found in our research supports suggestions by other researchers that some or many survivors of childhood sexual abuse may not exhibit significant symptoms as a result of the abuse at the times of participation in studies (Kendall-Tackett et al. 1993; Lynskey and Fergusson 1997; Mullen et al. 1994). This is very positive news for survivors of childhood sexual abuse, their loved ones, and professionals that provide help. We certainly cannot ignore the atrocity of sexually abusing a child and the suffering experienced by many survivors of childhood sexual abuse. We are suggesting that a history of childhood sexual abuse is not an automatic determinant of problems in adulthood (Hunter 2006).

A third important contribution from this research is the description of a series of mechanisms for the transmission of negative symptoms to adult relationships. These mechanisms begin with a perception of the current impact of the past on an individual. Depression plays a key role in carrying forward the negative influence of the past. Finally, negative emotional coping and interactions with conflict continue the indirect influence of childhood sexual abuse. Most importantly, the identification of these mechanisms provides identification of key points for interventions. We turn to these implications next.

\section{Treatment Implications}

Points of Intervention

For an adult or couple (one or both) presenting with childhood abuse and stress, our research suggests that clinicians explore the perception of current impact regarding negative events, such as childhood sexual abuse. In our research, most of the influence of childhood factors went through the adults' current perceptions and feelings about 
the impact of issues from their families of origin; and this factor was significantly related to current levels of depression and emotional flooding during couple conflict. Thus, all three adult affect variables can be points of intervention.

It can be beneficial to include adult partners in the treatment of adult childhood sexual abuse survivors (Bacon and Lein 1996; Chauncey 1994; Hughes 1994). This is particularly recommended if relational problems such as emotional flooding during conflict and low relationship satisfaction are identified symptoms.

\section{A Method of Therapy}

While a number of cognitive or behavioral-cognitive approaches present appropriate treatment options, the emotionally focused couple therapy (EFT) approach seems particularly suitable, given our findings that the effects of childhood emotion-laden events and processes "reach into" the adult relationship via emotionally loaded adult individual and relationship factors. Johnson's (2004) EFT approach focuses "on the relationships between partners in terms of the emotional bond" (p.7), and draws upon attachment theory for its theoretical underpinnings. A major goal of EFT is "to address attachment concerns, reduce attachment insecurities, and foster the creation of a secure bond" (p.39). The approach is a synthesis of the humanistic experiential perspective and family systems perspective to therapy. These combined approaches focus on "how to help partners reprocess and expand their experience and... modify their interaction patterns" (p.41).

Adult intimate relationships have a great potential for fostering hardiness within adult survivors of childhood sexual abuse as couples begin to recognize how they can influence relational interactions and partners begin understanding and validating each others' emotional experiences. Given the EFT focus, goals, and approach, and given our findings, we recommend this method of therapy as having particular efficacy for the issues we have investigated.

Another treatment consideration is the interaction of childhood factors with adult life factors, which may be a mixture of multiple effects, including some that reinforce each other in positive or negative ways. For example, adult depressed mood has multiple direct and indirect contributing sources and may be associated with multiple adult variables. For that reason, mental health treatment must keep a broad view of potential factors from childhood and adulthood, even when the initial focus is a single issue of depression. Simply treating depressed mood would not account for impact of childhood, which may be contributing to other challenges. Treatment of issues from a violent home would not account for the contributions of childhood stressors and childhood sexual abuse. Therefore, a thorough history is recommended and inclusion of all past trauma and current ineffective coping methods is valuable.

Finally, the factors determining who does and who does not experience later effects are complicated, but mental health workers should not assume that childhood sexual abuse alone will significantly impact everyone who reports this history. Assessing the perceived impact of negative childhood experiences may be a more reliable measure of who does and who does not experience later effects of childhood trauma. As we noted earlier, this is not meant in any way to suggest that childhood sexual abuse is harmless or trivial, only that we can not assume any specific correlations for any specific person. Also, it may not be wise to focus on childhood sexual abuse at the expense of other childhood and adult-related trauma and stressors that may be influencing the adult as much and possibly more then childhood sexual abuse.

\section{Limitations and Future Research}

Implications from our findings are limited due to characteristics of the data. As cross-sectional data obtained exclusively through the Internet and not representative of all populations, we can not say that the same statistical strengths apply to all populations. We also can not say that the statistical patterns will apply to everyone individually. Future research should compare individuals with varying degrees of abuse severity. It may be found that the paths will be stronger and more direct paths may be found as significant. Ideally, research would include longitudinal data from pre-relationships, even from childhood through relationship formation and through multiple assessments to catch the patterns of changes in relationship quality. Other childhood factors, such as relationships with parents and other adult variables, should also be considered to test for affect-absorbing or mediating variables.

Acknowledgement We acknowledge the financial support of the Family Studies Center and the School of Family Life at Brigham Young University.

\section{References}

Bacon, B., \& Lein, L. (1996). Living with a female sexual abuse survivor: male partners' perspectives. Journal of Child Sexual Abuse, 5(2), 1-16. doi:10.1300/J070v05n02_01.

Berliner, L., \& Elliott, D. M. (2002). Sexual abuse of children. In J. E. Myers, L. Berliner, J. Briere, C. T. Hendrix, C. Jenny \& T. A. Reid (Eds.), The APSAC handbook on child maltreatment (2nd ed., pp. 55-78). Thousand Oaks, CA: Sage.

Bowlby, J. (1973). Attachment and loss: II. Separation anxiety and anger. New York: Basic Books.

Busby, D. M., Holman, T. B., \& Taniguchi, N. (2001). RELATE: relationship evaluation of the individual, family, culture, and 
couple contexts. Family Relations, 50(4), 308-316. doi:10.1111/ j.1741-3729.2001.00308.x.

Busby, D. M., Gardner, B. C., \& Taniguchi, N. (2005). The family of origin parachute model: landing safely in adult romantic relationships. Family Relations, 54(2), 254-264. doi:10.1111/j.01976664.2005.00020.x.

Busby, D. M., Holman, T. B., \& Walker, E. C. (2008). Pathways to relationship aggression between adult partners. Family Relations, 57, 72-83.

Byrne, B. M. (2001). Structural equation modeling with AMOS. Mahwah, NJ: Lawrence Erlbaum Associates.

Chauncey, S. (1994). Emotional concerns and treatment of male partners of female sexual abuse survivors. Social Work, 39(6), 669-676.

Cherlin, A. J., Burton, L. M., Hurt, T. R., \& Purvin, D. M. (2004). The influence of physical and sexual abuse on marriage and cohabitation. American Sociological Review, 69(6), 768-789.

Colman, R. A., \& Widom, C. S. (2004). Childhood abuse and neglect and adult intimate relationships: a prospective study. Child Abuse \& Neglect, 28(11), 1113-1151. doi:10.1016/j.chiabu.2004.02.005.

Davila, J., Karney, B. R., Hall, T. W., \& Bradbury, T. N. (2003). Depressive symptoms and marital satisfaction: within-subject associations and the moderating effects of gender and neuroticism. Journal of Family Psychology, 17(4), 557-570. doi:10.1037/0893-3200.17.4.557.

Dennerstein, L., Guthrie, J. R., \& Alford, S. (2004). Childhood abuse and its association with mid-aged women's sexual functioning. Journal of Sex \& Marital Therapy, 30(4), 225-234. doi:10.1080/ 00926230490422331.

DiLillo, D., \& Long, P. J. (1999). Perceptions of couple functioning among female survivors of child sexual abuse. Journal of Child Sexual Abuse, 7(4), 59-76. doi:10.1300/J070v07n04_05.

Dong, M., Anda, R. F., Felitti, V. J., Dube, S. R., Williamson, D. F., Thompson, T. J., et al. (2004). The interrelatedness of multiple forms of childhood abuse, neglect, and household dysfunction. Child Abuse \& Neglect, 28(7), 771-784. doi:10.1016/j. chiabu.2004.01.008.

Dube, S. R., Anda, R. F., Felitti, V. J., Chapman, D. P., Williamson, D. F., \& Giles, W. H. (2001). Childhood abuse, household dysfunction, and the risk of attempted suicide throughout the life span. JAMA: Journal of the American Medical Association, 286(24), 3089-3096. doi:10.1001/jama.286.24.3089.

Edwards, J. J., \& Alexander, P. C. (1992). The contribution of family background to the long- term adjustment of women sexually abused as children. Journal of Interpersonal Violence, 7(3), 306320. doi: $10.1177 / 088626092007003002$.

Feinauer, L., Hilton, H. G., \& Callahan, E. H. (2003). Hardiness as a moderator of shame associated with childhood sexual abuse. The American Journal of Family Therapy, 31(2), 65-78. doi:10.1080/ 01926180301125.

Finkelhor, D., Hotaling, G. T., Lewis, I. A., \& Smith, C. (1990). Sexual abuse in a national survey of adult men and women: prevalence, characteristics, and risk factors. Child Abuse \& Neglect, 14, 19-28. doi:10.1016/0145-2134(90) 90077-7.

Holman, T. B. (2001). Premarital prediction of marital quality or breakup. New York: Kluwer Academic/Plenum Publishers.

Hughes, M. M. (1994). Using the couple relationship to address childhood sexual abuse. The Family Journal (Alexandria, Va.), 2 (2), 114-121. doi:10.1177/1066480794022004.
Hunter, S. V. (2006). Understanding the complexity of child sexual abuse: a review of the literature with implications for family counseling. The Family Journal (Alexandria, Va.), 14(4), 349358. doi:10.1177/1066480706291092.

Jack, L. A., Dutton, D. G., Webb, A. N., \& Ryan, L. (1995). Effects of early abuse on adult affective reactions to exposure to dyadic conflict. Canadian Journal of Behavioural Science, 27(4), 484 500. doi:10.1037/0008-400X.27.4.484.

Johnson, S. M. (2004). The practice of emotionally focused couple therapy. New York: Brunner-Routledge.

Kendall-Tackett, K. A., Williams, L. M., \& Finkelhor, D. (1993). Impact of sexual abuse on children: a review and synthesis of recent empirical studies. Psychological Bulletin, 113, 164-180. doi:10.1037/0033-2909.113.1.164.

Koopman, C., Gore-Felton, C., Classen, C., Kim, P., \& Spiegel, D. (2001). Acute stress reactions to everyday stressful life events among sexual survivors with PTSD. Journal of Child Sexual Abuse, 10(2), 83-99. doi:10.1300/J070v10n02 05.

Larson, J. H., \& Lamont, C. (2005). The relationship of childhood sexual abuse to the marital attitudes and readiness for marriage of single young adult women. Journal of Family Issues, 26(4), 415430. doi: $10.1177 / 0192513$ X04270474.

Lawson, R., Drebing, C., Berg, G., Vincellette, A., \& Penk, W. (1998). The long term impact of child abuse on religious behavior and spirituality in men. Child Abuse \& Neglect, 22(5), 369-380. doi:10.1016/S0145-2134(98) 00003-9.

Lynskey, M. T., \& Fergusson, D. M. (1997). Factors protecting against the development of adjustment difficulties in young adults exposed to childhood sexual abuse. Child Abuse \& Neglect, 21 (12), 1177-1190. doi:10.1016/S0145-2134(97) 00093-8.

Martinson, V. K. (2005). How coming to terms with difficulties in the family of origin positively influences adult children's relationship/marital quality. Unpublished doctoral dissertation, Brigham Young University.

Mullen, P. E., Martin, J. L., Anderson, J. C., Romans, S. E., \& Herbison, G. P. (1994). The effects of child sexual abuse on social, interpersonal and sexual function in adult life. The British Journal of Psychiatry, 165, 35-47. doi:10.1192/bjp. 165.1.35.

Simpson, J. A., Collins, W. A., Tran, S., \& Haydon, K. C. (2007). Attachment and the experience and expression of emotions in romantic relationships: A developmental perspective. Journal of Personality and Social Psychology, 92(2), 355-367.

Sroufe, L. A., Egeland, B., Carlson, E. A., \& Collins, W. A. (2005). The development of the person. New York: Guilford.

Swanston, H. Y., Plunkett, A. M., O’Toole, B. I., Shrimpton, S., Parkinson, P. N., \& Oates, R. K. (2003). Nine years after child sexual abuse. Child Abuse \& Neglect, 27, 967-984. doi:10.1016/ S0145-2134(03) 00143-1.

Twaite, J. A., \& Rodriguez-Srednicki, O. (2004). Childhood sexual and physical abuse and adult vulnerability to PTSD: the mediating effects of attachment and dissociation. Journal of Child Sexual Abuse, 13(1), 17-38. doi:10.1300/J070v13 n01_02.

Whisman, M. A., Uebelacker, L. A., \& Weinstock, L. M. (2004). Psychopathology and marital satisfaction: the importance of evaluating both partners. Journal of Consulting and Clinical Psychology, 72, 830-838. doi:10.1037/0022-006X.72.5.830. 